American Journal of Economics and Business Administration 3 (2): 416-419, 2011

ISSN 1945-5488

(C) 2011 Science Publications

\title{
Information System Analysis and Building for Integrated Real Estate Business Management in Real Estate Market
}

\author{
Hassan Mohammed M. Elmetwaly \\ Department of Computer Science and Information Technology, \\ King Faisal University, P.O. Box 5372, Alhasa 31982, Kingdom of Saudi Arabia
}

\begin{abstract}
Problem statement: This study discusses the problem of registration and following-up the real estate rental procedures of all kinds, always what we need is integrated information systems to meet our daily needs in the area of our business. Approach: Proposed information systems includes all of these processes necessary to manage and follow up real estate rental procedures of all different sizes and spaced locations. Results: It is taken into account when building real estate information systems that to be easy to use, quick in performance, serve all interests, serve all officials and help in having and supporting decisions. Such real estate information systems can be used in producing numerous daily, monthly and annual reports, which describes and shows the movement and workflow. Conclusion/Recommendations: The proposed real estate system is built by using oracle databases, it has been taken into account when building these systems the need to be linked to the international information network "the internet" due to what is offered of the unlimited number of electronic services, which facilitate the movement of transferring and exchanging real estate information for all users of these systems.
\end{abstract}

Key words: Real Estate Business Management (REBM), E-Systems ORACLE, Structured Query Language (SQL), information system, international information, oracle databases, information systems

\section{INTRODUCTION}

The process of developing information systems is the most important objective of the Real Estate developers wok in this field of real estate development. It is well known to all that any information systems always need to be developed continuously and to address all the problems that may arise to work. This proposed system was built several years ago and has been tested in several real estate companies and offices in several and different countries. This research discusses how to take advantage of modern technology available and how to use Oracle databases to save all the data and real estate information that will be used. It also has been taken into account when building this proposed system that to be easy in access to the data and speediness in performing orders and recalling information reports and customer accounts. Given to the importance of time in order to help decision-makers carrying out the necessary procedures and appropriate to the real estate market situation, especially if there are means enabling access information via the Internet. Helping staff, data entry and all employees on these ESystems to exchange information is the most important goal and priorities sought by everyone, so it has been taken into account the use of oracle databases because they are considered one of the best databases that enable us to share data and information required readily and easily at any time, according to the powers granted to each user of real estate. Information systems. The ext question is the extent to which all office space will be included in the model. Will the model include government-owned office buildings and private buildings occupied by government employees? Will the model include private owner-occupied buildings? Will buildings only above a certain size be included? What about office space that is included in buildings that primarily house other types of activities (such as offices in factories)? Are Class A, Class B and Class C rental buildings to be included, or just Classes A and B? Model builders have made somewhat different choices on these questions, which have largely been answered by the nature of the data that are available. Econometric models of office markets must rely primarily on data generated and supplied by private sources (McDonald, 2002). published a special issue of the Journal of the American Real Estate and Urban Economics Association office market research These AREUEA publications signaled the need for much more research, especially empirical research and a large number of

Corresponding Author: Hassan Mohammed, Department of Computer Science and Information Technology, King Faisal University, P.O. Box 5372, Alhasa 31982, Kingdom of Saudi Arabia 
researchers in the field have responded. As the list of references to this article indicates, leading academic researchers in the U.S. have devoted a great deal of time to this task over the past decade (Pollakowski et al., 1980). Most of the econometric models of office market use the metropolitan area as the geographic scale, although some models have been estimated at the national level (King and McCue, 1987). A perfect macro-control system can be described as a system that is used by governments to intervene in and control the overall economic supply and demand of an entire society via economic, legal, administrative and information-oriented measures. It is an organic and interactive system that consists of control organs, control objects, control measures and control poicies (Xu and Zheng, 2000; Li and Ma, 2002).

\section{MATERIALS AND METHODS}

We have taken into account when building the proposed real estate information systems to meet the needs of all workers in this real estate field of receiving applications, registering tenants files, personal and accounting customers and tenants data, owners accounts and registering all data properties with different types by using these proposed regulations. Oracle databases help all workers in this field of programmers and databases developers in preserving and protecting all data and information and managing the smooth delivery to those in need upon request through the large number of reports that have been built, which was added to the real estate information systems to after being tested and tried several times on a large number of specialists in this field, such as real estate companies and firms and even small real estate offices . Our dire need to use new tools and that may help us complete all required daily works always urges us search for proper solutions with less charges. Systems' analyzers and software engineers often resort to innovate every and each new and useful things in this respect (Hassan et al., 2010). Until recently there has been less emphasis on the interactive models needed by these environments (Bellotti et al., 2002). This research discusses how to utilize modern technologies available and Oracle databases to be available in early future, to be both utilized and exchanged among concerned parties (Hassan and Elmetwaly, 2010). The AngloAmerican method is of economic provenience. It models the interdependence of supply (the total stock) and demand (the occupied space). Since an exact balance of the market via prices does not work due to small demand elasticity and an adaptation of new construction rates takes effect after approximately three years (not considering the fragmented structure of suppliers without information from each other that fosters the genesis of market cycles), it is the vacancy rate which adapts the quickest. Out of the huge quantity of papers (Hysom, 1997). A real estate macro-control system that is based on information systems is a type of macro-control system in which warning systems, confidence indexes and simulation systems are regarded as the leading control measures and, at the same time, economic, legal and administrative measures are synthetically applied to the macro control of the REM (Li and Ma, 2002).

\section{RESULTS}

- The proposed real estate information systems have been built and designed by using Oracle Database $10 \mathrm{~g}$

- All data entry forms has been built using oracle developer through which all data can be entered and recorded in the computer

- There is an integrated system to manage and monitor users of real estate information systems

- The information system can be used through the international information network "Web-Based" by means of models designed by ASP.NET

- All these information systems users can exchange data easily and smoothly

- There is a system for managing and following up the owners accounts enclosed with these information systems

- There is also a system for following up the tenants account and providing with required reports

- There is a large number of reports that show the performance movement and daily workflow

- The possibility of producing Graphics from this real estate information system

\section{DISCUSSION}

The proposed real estate information systems have passed by several stages including the first phase: The phase of collecting data and information about the real estate systems available in the market, the second phase: Conducting a study of these systems and to gather as much as possible of the advantages and disadvantages that can even benefit from the advantages and avoid disadvantages and problems so as not to fall in or be repeated when building the information systems, the third phase: To convert all the previous information to the databases and that built using Oracle, the fourth stage: Phase of building the input forms ORFMS by using also ORACLE DEVELOPER. 


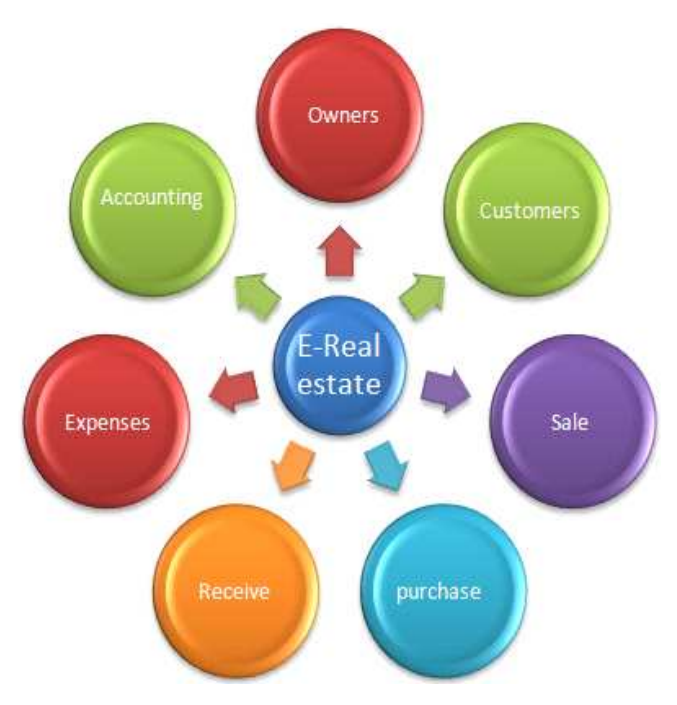

Fig. 1: E-real estate processes

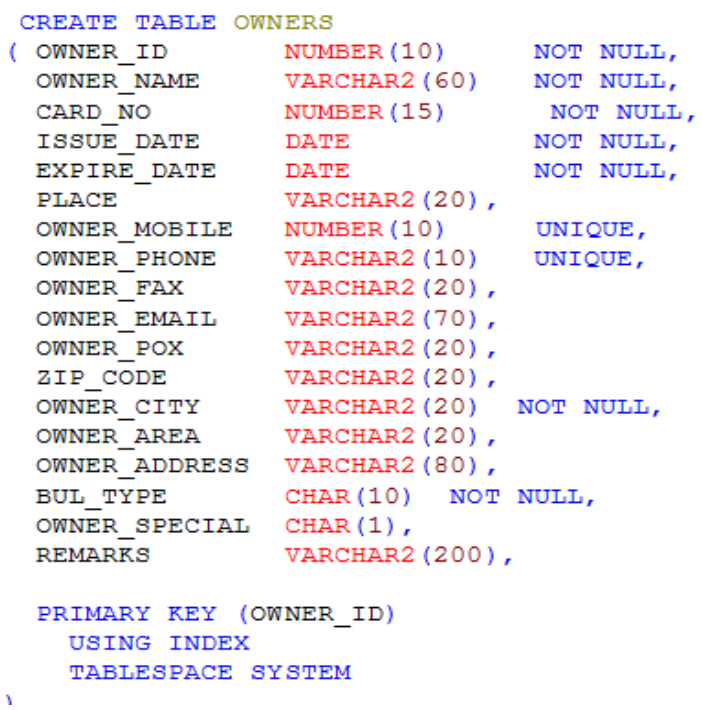

Fig. 2: Owners table in database

Given to the content of the strength and durability and high speed accuracy in the results. The fifth phase: Is the stage of building the necessary reports to illustrate the movement and progress of daily work and to assist decision makers to build real estate decisions, which would raise the efficiency and development of business in the real estate market. Sixth phase "training stage": Users are trained on how to deal with the study management and follow-up by using the proposed Real Estate Information Systems. Seventh phase: the stage of collecting notes and proposals relevant to workers on real systems work and study and try to implement and add to the information systems.

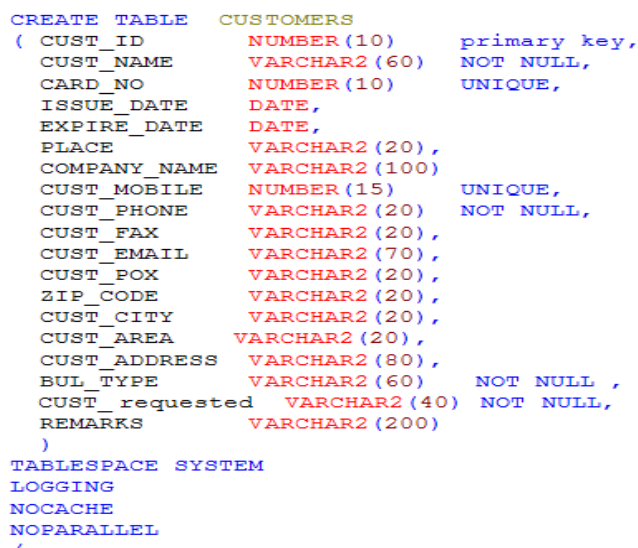

Fig. 3: Customers table in database

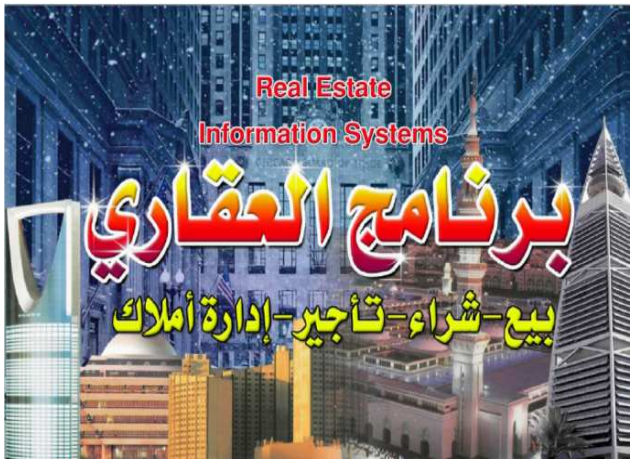

Fig. 4: The main screen of real estate information systems

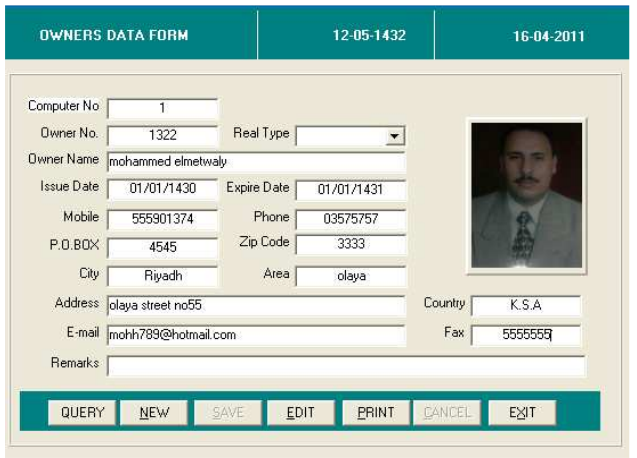

Fig. 5: Owners registration form

Eighth phase: the stage of development of real estate and information systems in order to keep pace with the enormous and amazing developments in the field of information technology. Figure 1 E-Real Estate Processes. Figure 2 Owners Table In Database. Figure 3 shows the Flow Chart to follow up the new lease contracts registration or edit. Figure 4 the Main Screen of Real Estate Information Systems. Figure 5 is an Owners Registration Form. Figure 6 is a contract registration form. 


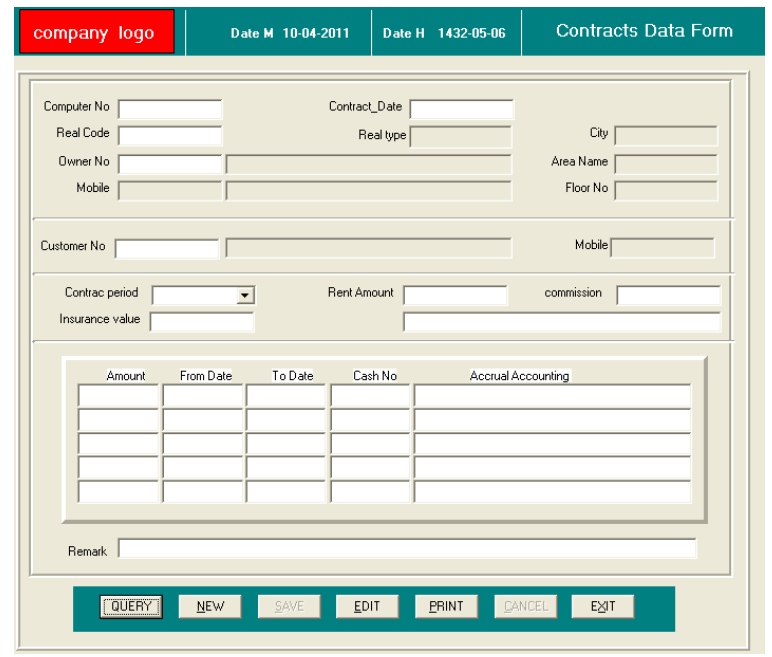

Fig. 6: Contract registration form.

\section{CONCLUSION}

The main objective of the proposed electronic system is to facilitate the entry and follow-up data of landlords and tenants and all properties, noting that the system was designed by using the oracle database. Given to the advantage of the volume of data that can be held and the large number of users who can access the databases at any time and achieve their business. Also this system has the advantage of possibility of follow-up and management of real estate business smoothly and easily. The process of software development always requires to make more and more effort in order to reach the desired goals and try to simplify procedures and shorten the time and effort in reaching the results.

\section{REFERENCES}

Bellotti, V., M. Back, W. Edwards, K. Grinter and R.E. Henderson et al., 2002. Sense of sensing systems: Five questions for designers and researchers. Proceedings of the SIGCHI conference on Human Factors in Computing Systems: Changing our World, Changing Ourselves, Apr. 20-25, Minneapolis, MN, USA., pp: 415-422. DOI: $10.1145 / 503376.503450$
Hassan, M., M. Elmetwaly, 2010. Proposed Movement, Tracking e-systems of payment in the municipalities. J. Comput. Sci., 6: 572-575. ISSN: 1549-3636.

http://www.scipub.org/fulltext/jcs/jcs65572575.pdf

Hassan, M. and M.A. Elmetwaly, 2010. System, for elearning processes management. J. Comp. Sci., 6: 687-690. ISSN: 1549-3636, http://www.scipub.org/fulltext/jcs/jcs67689692.pdf

Hysom, C., 1997. The evolution of office building research. J. Real Esta. Liter., 145-157. http://business.fullerton.edu/finance/jrel/papers/pdf/ past/1997vol5n2/ReviewA ticle145_157.pdf

McDonald, J.F., 2002. A survey of econometric models of office markets. J. Real Estate Literature, 10: 223242.

http://business.fullerton.edu/finance/jrel/papers/pdf/ past/2002vol10n2/02.223_242.pdf

King, J. and T. McCue, 1987. Office building investment and the macroeconomy: Empirical evidence. J. Am. Real Esta. Urb. Econ. Assoc., 15: 234-255. http://www.blackwell synergy.com/doi/abs/10.1111/1540-6229.00430

$\mathrm{Li}, \mathrm{T}$. and Y. Ma, 2002. Advice to the harmonious development of the real estate industry and national economy in China. J. Harbin Univ. Commerce, 4: 33-36.

Pollakowski, H., S. Wachter and L. Lynford, 1980. Did office market size matter in the s? A time-series cross-sectional analysis of metropolitan area office markets. J. Am. Real Esta. Urb. Econ. Assoc., 303324. URL: http://www.blackwellsynergy.com/doi/abs/10.1111/1540-6229.00586

Xu, Y.M. and X.Y. Zheng, 2000. Some considerations of macroscopic readjustment and control to real estate development. J. Chong. Jianz. Univ. 2: 3033.

http://www.umac.mo/fba/irer/papers/past/vol12n2_ pdf/05.pdf 